\title{
TEOLOGI PEMBEBASAN DALAM ISLAM: Telaah Pemikiran Asghar Ali Engineer
}

\author{
M. Kursani Ahmad \\ Jurusan Akidah Filsafat Fakultas Ushuluddin IAIN Antasari \\ Jl. A. Yani Km. 4,5 Banjarmasin
}

\begin{abstract}
Abstrak
Teologi Pembebasan dalam konteks pemikiran Islam kontemporer mencuat ke permukaan sebagai sebuah keniscayaan sejarah. Paradigma ini muncul seiring dengan adanya fenomena sosial yang berupa keterbelakangan, ketinggalan, kemiskinan, ketidakadilan dan kebodohan masyarakat Islam dibandingkan dengan masyarakat non Islam. Banyak pemikir Islam kontemporer merasa gelisah dan berusaha mencari penyelesaian atas realitas yang dihadapi masyarakat Islam tersebut. Asghar Ali Engineer salah seorang pemikir Islam kontemporer, dan sebagai pelopor yang menawarkan paradigma pembebasan ke dalam teologi, yang ditransformasikan menjadi tiga konsep kerangka praksis, yaitu taubid, iman dan jihad.
\end{abstract}

Kata kunci: teologi pembebasan, ketidakadilan, taubid, iman dan jihad.

\section{Pendahuluan}

Tersebarnya Islam yang dibawa oleh nabi Muhammad saw. di permukaan bumi ini, dimana kedatangannya merupakan sebuah revolusi yang selama berabad-abad telah berperan secara sangat signifikan dalam panggung sejarah kehidupan umat manusia. Islam hadir untuk menyelamatkan, membela dan menghidupkan keadilan dalam bentuknya yang paling konkret. Dengan demikian Islam bermakna sebagai pembebas, yaitu membebaskan manusia dari kondisi-kondisi ketidakadilan. Hal ini sebagaimana diajarkan dalam al-Qur'an dan hadis-hadis Nabi saw. yang secara tersurat maupun tersirat, langsung atau tidak langsung menggugat kondisi-kondisi ketidakadilan yang terjadi di tengah masyarakat, bangsa dan negara.

Setelah nabi Muhammad saw. wafat, terjadilah perubahan dengan timbulnya perebutan kekuasaan yang berorientasi kepada kepentingan pribadi dan golongan. Kemudian tampillah orang-orang yang mengingin- 
kan status quo, sehingga Islam menjadi hilang daya revolusioner yang telah dimilikinya sampai sedemikian jauh. Sejak itulah, perhatian umat lebih tercurah pada masalah-masalah teologi, ketimbang masalah sosial dan ekonomi. Kondisi ini ditambah lagi dengan persinggungan antara Islam dan Ilmu pengatahuan Yunani, yang tentunya dapat menimbulkan dampak positif dan negatif. Di samping itu kalangan elit Islam semakin bersemangat untuk melakukan intellectual exercise yang bersifat spekulatif. Selanjutnya, Islam yang revolusioner itu menjadi hilang vitalitasnya. Sekolah-sekolah teologi dan hukum mulai menancapkan eksistensinya, dan bersamaan dengan itu, Islam tidak lagi memperdulikan masalah-masalah keadilan sosio-ekonomi. Umat Islam hanya menyisakan sedikit rasa peduli terhadap golongan yang lemah, dan lenyapnya elan vital keadilan Islam yang distributif. ${ }^{1}$

Selama ini kita hanya mengenal dua paradigma teologi yang masih berlaku di dunia Islam, yakni paradigma Asy'ariyah dan Salafiyah. Paradigma Asy'ariyah lebih banyak penganutnya daripada paradigma Salafiyah. Sementara paradigma Asy'ariyah dan Salafiyah saling berebut pengaruh, hal ini memunculkan paradigma kritis Ali Shariati dan Asghar Ali Angineer yang menginginkan adanya paradigma baru dalam teologi, yang tujuannya jelas-jelas membela masyarakat yang tertidas. Paradigma ini menggagas sebuah paradigma teologi yang lebih memihak kaum papa, yang kemudian dikenal dengan teologi pembebasan. ${ }^{2}$

Dengan demikian, dalam konteks pemikiran Islam kontemporer, paradigma teologi pembebasan ini mencuat kepermukaan sebagai sebuah keniscayaan sejarah. Paradigma ini muncul seiring dengan adanya fenomena sosial berupa keterbelakangan, ketinggalan, kemiskinan, ketidakadilan, dan kebodohan masyarakat Islam dibandingkan masyarakat non Islam lainnya. Banyak pemikir Islam kontemporer merasa gelisah dan berusaha mencari penyelesaian atas realitas yang sedang dihadapi masyarakat Islam tersebut. Dalam konteks ini, kita mengenal pemikir-pemikir seperti Hasan Hanafi yang mencetuskan ide al-Yasar al-Islami (1981), Ziaul Haque dengan Revela-

\footnotetext{
${ }^{1}$ Asghar Ali Engineer, Islam dan Teologi Pembebasan, Terj. Agung Prihantoro, (Yogyakarta: Pustaka Pelajar, 2003), h. x.

${ }^{2}$ Muhyar Fanani, Metode Studi Islam Aplikasi Sosiologi Pengetabuan Sebagai Cara Pandang, (Yogyakarta: Pustaka Pelajar, 2008), h. 143.
} 
tion and Revolution (1992), dan Asghar Ali Engineer dengan Islam and Liberation Theology (1990). ${ }^{3}$

Sehubungan dengan itu, maka dalam tulisan ini akan dikupas dan dianalisis tawaran konstruksi pemikiran yang dibangun oleh Asghar Ali Engineer (selanjutnya disebut Engineer), yang telah menarik paradigma pembebasan ke dalam teologi.

\section{Riwayat Hidup dan Karir Intelektual Engineer}

Engineer dilahirkan pada tanggal 10 Maret 1939 di Rajasthan di daratan India, dalam sebuah keluarga yang berafiliasi kepada paham Syi'ah Ismailiyah ${ }^{4}$. Engineer lahir dari keluarga santri, Dia belajar bahasa Arab dari ayahnya, syekh Qurban Husin dan mendapatkan pendidikan sekuler hingga memperoleh gelar sarjana teknik sipil dari Unversitas of Indore. Dalam perjalanan hidupnya Engineer sendiri pernah menjadi pemimpin komunitas Syiah Ismailiyah Bohra yang cukup terkenal di India. Di samping itu, Engineer pernah menjabat Sekretaris Jenderal Dewan Pimpinan Komunitas Daudi Bohras (1977), pendiri Institut of Islamic Studies di Mumbai (1980), dan ikut mendirikan Center for the Study of Society and Secularism (1993) ${ }^{5}$

Untuk lebih memahami latar belakang keagamaan Engineer, ada baiknya diketahui sepintas tentang kelompok Daudi Bohras ini. Para pengikut Daudi Bohras dipimpin oleh Imam sebagai pengganti Nabi yang dijuluki Amir al-Mukminin. Mereka mengenal 21 orang Imam. Imam mereka yang terakhir adalah Mawlana Abu al-Qasim al-Thayyib yang menghilang pada tahun $526 \mathrm{H}$. Akan tetapi mereka masih percaya bahwa ia masih hidup hingga sekarang. Kepemimpinannya dilanjutkan oleh para Da'i (berasal dari ungkapan Daudi) yang selalu berhubungan dengan Imam terakhir itu. Untuk diakui sebagai Da’i tidaklah mudah. Ia harus mempunyai 94 kualifikasi yang disimpulkan menjadi 4 kualifikasi, yaitu, pendidikan,

${ }^{3}$ Muhammad In Am Esha, Rethinking Kalam: Sejarah Sosial Pengetahuan Islam, Mecermati Dinamika dan Aras Perkembangan Kalam Kontemporer, (Yogyakarta: eLSAQ Press, 2006), h. 73.

${ }^{4}$ M. Agus Nuryatno, Asghar Ali Engineer: Sang Teolog Pembebasan, dalam http:/ / www. mailarchive.com/kmnu2000@yahoogroups.com/msg01, h. 1.

${ }^{5}$ Nugroho Dewanto dan Iqbal Muhtarom, Anti MUI: Islam Yes, MUI No, Surga Bukan Monopoli Muslim, Wawancara dengan Asghar Ali Engineer, Majalah Tempo, 20 Agustus 2008, h. 6 . 
administrasi, moral dan teoritikal, keluarga dan kepribadian. Yang menarik bahwa di antara kualifikasi itu seorang Da'i harus tampil sebagai pembela umat yang tertindas dan berjuang melawan kezaliman. Untuk itu Engineer diakui sebagai seorang Da'i. ${ }^{6}$

Engineer yang diakui sebagai Da'i, juga sebagai seorang ilmuan terkenal yang menguasai banyak bahasa, di antaranya bahasa Inggris, Urdu, Arda, Persia, Gujarat, Hindu dan Marathi. Dan dia banyak memberikan kuliah di berbagai universitas terkenal, seperti di Amerika Serikat, Kanada, Inggris, Swiss, Thailand, Malaysia, Srilangka, Pakistan, Yaman, Mesir dan Hongkong. ${ }^{7}$ Pada bulan Agustus tahun 2008, Engineer pernah berkunjung ke Indonesia, dan menyampaikan ceramah tentang Islam dan Negara Bangsa, serta bertemu dengan sejumlah cendekiawan Islam Indonesia, antara lain mantan presiden Abdurrahman Wahid. ${ }^{8}$

Djohan Effendi tampak sangat tertarik terhadap pemikiran Engineer, menurut Djohan, Engineer adalah seorang mukmin sejati bukanlah sekedar orang yang percaya kepada Allah akan tetapi juga ia seorang mujahid yang berjuang menegakkan keadilan, melawan kezaliman dan penindasan. ${ }^{9}$

Sebagai seorang pemikir, Engineer telah menerbitkan puluhan buku dengan berbagai tema. Di antara karya-karya tersebut antara lain: Islam and Its Relevance to Our Age, The Oringin and Development of Islam, Islam and Muslims: Critical Perspectives, The Bohras, The Islamic State, Islam and Liberation Theology, On Developing Liberation Theology in Islam, Islam in South-East Asia, Seminar on Sufism and Communal Harmony, The Spirituality of Social Movement, Rights of Women in Islam, Communalism and Communal Violence in India, Ethnic Problem in South Asia, The Qur'an, dan Women and Modern Society. Selain itu Engineer juga menulis beberapa artikel beberapa surat kabar terkemuka

${ }^{6}$ Djohan Effendi, “Memikirkan Kembali Asumsi Pemikiran Kita,” Kata Pengantar: Asghar Ali Engineer: Islam dan Pembebasan, dalam http:// media.isnet.org/islam/Etc/Pengantar, h. 2 .

${ }^{7}$ Jamal Syarif, Pemikiran Asghar Ali Engineer Tentang Hak-Hak Perempuan Dalam Islam, Khazanah Jurnal Ilmiah Keislaman dan Kemasyarakatan, Volume III Nomor 1, JanuariPebruari 2004, (Banjarmasin: IAIN Antasari, 2004), h. 103.

${ }^{8}$ Nugroho Dewanto dan Iqbal Muhtarom, Anti MUI:........, h. 1.

${ }^{9} \mathrm{Ahmad}$ Gaus AF, Sang Pelintas Batas Biografi Djohan Effendi, Jakarta: ICRP dan Kompas, 2009), h. 313. 
di India, seperti Times of India, Indian Express, The Hindu Daily, Telegraph, dan Indian Jurnal of Secularism..$^{10}$

Di luar aktivitas intelektual, Engineer adalah seorang aktivis sosial, di antara jabatan penting yang dipercayakan kepadanya, antara lain: Wakil Presiden pada People's Union for Civil Liberties, Pemimpin Rikas Adhyayan Kendra (Centre for Development Studies), Pemimpin EKTA, (Committee for Communal Harmony), Ketua pendiri pada Centre for Study of Society and Secularism, Mantan Dewan Eksekutif Universitas of Jawaharlal New Selhi, dan Sekretaris Umum pada Central Board of Dewood di Bohra Community and Cenvenor Asian Muslim Action Network (AMAN). ${ }^{11}$ Dan tercatat pula Engineer pernah memberikan kuliah di Universitas berbagai Negara seperti Amerika, Kanada, Inggris, Swiss, Thailand, Malaysia, Indonesia, Sri Lanka, Pakistan, Yaman, Hongkong, dan Mesir. ${ }^{12}$

Karena pemikiran dan aktivitas sosialnya Engineer memperoleh beberapa penghargaan, antara lain: Gelar kehormatan D.Lit. dari Universitas Calcuta, National Communal Harmony Award dari National Foundation for Communal Harmony, Harmony Award dari New Leaders Commitee, Chennai, dan Hakim Khan Sur Award dari Maharana Mewar Foundation, Udaipur, Rajasthan. ${ }^{13}$

Adapun metode pemikiran Engineer bersifat normatif kontekstual dan transendental. Bersifat normatif, karena dia selalu mendasarkan pada ayat-ayat al-Qur'an sebagai sumber rujukan terhadap kasus-kasus sosial politik maupun teologi. Sedangkan kontekstual dimaksudkan untuk menafsirkan ajaran-ajaran agama yang bersifat normatif yang belum mengenal waktu dan tempat ke dalam sosio kultural yang ada, yaitu dengan cara membaca kondisi sosio masyarakat yang berlaku. Adapun yang bersifat transendental, karena ayat-ayat tersebut memerlukan pengetahuan yang cukup mendalam dan memahami antara teks dengan konteksnya.

Untuk mengetahui lebih dalam tentang teori yang ditetapkan oleh Engineer tersebut adalah teori sosio historis, dengan selalu membaca realita

\footnotetext{
${ }^{10}$ Muhammad In Am Esha, Rethinking Kalam:...., h. 78.

${ }^{11}$ Asghar Ali Engineer, Hak-hak Perempuan dalam Islam, Terj. Farid Wajidi, (Yogyakarta: Pustaka Pelajar, 2000), h. 295.

${ }^{12}$ Muhammad In Am Esha, Rethinking Kalam:....., h. 79.

${ }^{13}$ Muhammad In Am Esha, Rethinking Kalam:....., h. 79.
} 
yang ada dengan mengaitkan sejarah, tentang pemikiran-pemikiran masa lalu dengan masa modern. Pemikiran Engineer banyak dipengaruhi oleh pemikiran Karl Mark tentang pembebasan berpikir dan juga dipengaruhi oleh pemikiran Muhammad Iqbal yang modern. ${ }^{14}$

Dari sini dapat dipahami ada dua aspek fundamental yang mempengaruhi konstruksi pemikiran Engineer yaitu: Pertama, realitas sosiopolitik yang dialami oleh masyarakat India, disamping karena pengaruh pemikiran pembaharuan dan progresivitas para pemikir pendahulu, seperti Muhammad Iqbal. Kedua, paham keberagamaan yang dimilikinya sebagai pemimpin Syi'ah Ismailyah yang menekankan pembelaan dan pembebasan terhadap kaum tertindas.

\section{Konsep Islam tentang Teologi Pembebasan}

Islam adalah agama yang membawa rahmat bagi bagi sekalian alam terutama untuk umat manusia, Islam adalah sebuah agama dalam pengertian teknis dan sosial-revolutif yang menjadi tantangan bagi yang mengancam struktur yang menindas pada saat ini. Adapun tujuan dasarnya adalah persaudaraan yang universal (universal brotherhood), kesejahteraan (equality) dan keadilan sosial (social justice). Untuk itulah Islam sangat menekankan kesatuan manusia (unitiy of mankind).$^{15} \mathrm{Hal}$ ini telah ditegaskan oleh Allah dalam al-Qur'an, "Hai manusia, sesungguhnya Kami menciptakan kamu dari seorang laki-laki dan seorang perempuan dan menjadikan kamu berbangsa-bangsa dan bersuku-suku supaya kamu saling kenal mengenal. Sesungguhnya orang yang paling mulia di antara kamu di sisi Allah ialah orang yang paling bertakwa di antara kamu. Sesungguhnya Allah Maha Mengetahui lagi Maha Mengenal" (al-Qur'an, 49:13).

Menurut M. Quraish Shihab, ayat ini menegaskan kesatuan asal usul manusia dengan menunjukkan kesamaan derajat kemanusiaan manusia. Tidak wajar seseorang berbangga dan merasa diri lebih tinggi dari yang lain, bukan saja antarsatu bangsa, suku, atau warna kulit dengan selainnya, tetapi antarjenis kelamin mereka. ${ }^{16}$ Selain itu ayat di atas secara jelas mem-

${ }^{14}$ Jamal Syarif, Pemikiran Asghar Ali Engineer...., h. 105.

${ }^{15}$ Asghar Ali Engineer, Islam ..., h. 33.

${ }^{16} \mathrm{M}$. Quraish Shihab, Tafsir al-Mishbab Pesan, Kesan dan Keserasian al-Qur'an, Volume 13, (Jakarta: Lentera Hati, 2002), h. 261. 
bantah semua konsep superioritas rasial, kesukuan, kebangsaan atau keluarga, dengan satu penegasan dan seruan akan pentingnya kesalehan. Kasalehan yang dimaksud bukan hanya kesalehan ritual, namun juga kesalehan sosial. ${ }^{17}$

Di samping itu, Islam juga sangat menekankan pada keadilan di semua aspek kehidupan. Keadilan ini tidak akan tercipta tanpa membebaskan golongan masyarakat lemah dan marjinal dan penderitaan, serta memberi kesempatan kepada mereka untuk menjadi pemimpin. Oleh karena itu, Islam tidak ragu-ragu untuk mempercayakan kepemimpinan seluruh dunia kepada kaum mustadh'aifin, yakni kaum yang lemah. Hal ini telah ditegaskan Allah dalam al-Qur'an: "Dan Kami hendak memberikan karunia kepada orang-orang yang tertindas di bumi (Mesir) itu dan hendak menjadikan mereka pemimpin dan menjadikan mereka orang-orang yang mewarisi (bumi)".(al-Qur'an, 28: 5)

Demikian pula Islam memerintahkan kepada orang-orang yang beriman untuk berjuang membebaskan golongan masyarakat lemah dan tertindas. Sebagaimana tersebut dalam al-Qur'an: "Mengapa kamu tidak mau berperang di jalan Allah dan (membela) orang-orang yang lemah baik laki-laki, wanita-wanita maupun anak-anak yang semuanya berdo'a: "Ya Tuhan kami, keluarkanlah kami dari negeri ini (Mekah) yang zalim penduduknya dan berilah kami perlindungan dari sisi Engkau, dan berilah kami penolong dari sisi Engkau. (al-Qur'an, 4:75)

Ayat-ayat al-Qur'an yang turun di Mekah, dapat dirasakan dengan jelas kepedulian terhadap masyarakat yang menderita, dan sangat mengecam arogansi orang-orang kaya Mekah yang tidak peduli terhadap fakir, miskin dan anak-anak yatim. "Tahukah kamu (orang) yang mendustakan agama? Itulah orang yang menghardik anak yatim, dan tidak menganjurkan memberi makan orang miskin. (al-Qur'an,107:1-3) Pendekatan Qur'ani yang seperti ini tetap berlanjut sampai periode Madinah. Celaan yang keras terhadap penumpukan harta ini juga disebutkan dalam Surah at-Taubah yang turun di Madinah. "Dan orang-orang yang menyimpan emas dan perak dan tidak menafkahkannya pada jalan Allah, maka beritahukanlah

${ }^{17}$ Asghar Ali Engineer, Islam ..., h. 33. 
kepada mereka, (bahwa mereka akan mendapat) siksa yang pedih. (alQur'an, 9: 34)

Nabi Muhammad saw. membenci kemiskinan dan mewajibkan umat Islam untuk menyatakan perang terhadap kemiskinan. Kemiskinan itu sama celanya dengan kekafiran, dan karena seorang Muslim harus memerangi kufr, berarti ia juga harus memerangi kemiskinan. Membiarkan kemiskinan sama halnya dengan memelihara kekafiran. Paham atau sistem yang berusaha mengekalkan kemiskinan, kelaparan dan kekurangan, harus dilawan, karena akan mengarah pada feodalisme atau kapitalisme. Sehingga perang melawan kemiskinan merupakan bagian integral dari keyakinan Islam. ${ }^{18}$

Dengan demikian tantangan kemiskinan ini harus dijawab dengan membangun struktur sosial yang bebas dari eksploitasi, penindasan dan konsentrasi kekayaan pada segelintir tangan saja. Dalam struktur sosial seperti ini, terdapat nilai kebenaran yang lain yaitu keadilan di bidang sosial, ekonomi, hukum dan politik. Keadilan dan keseimbangan ekonomi ini diperlukan, karena dengan demikian berarti kebutuhan pokok, seperti makanan, tempat tinggal dan seterusnya dapat dipenuhi, sehingga kecenderungan gaya hidup boros dapat ditekan. ${ }^{19}$

\section{Pemikiran Engineer tentang Teologi Pembebasan}

Dalam sebuah artikel yang berjudul "What I Belive” (Mumbay: 1999), Engineer mengemukakan tiga pokok persoalan yang mendasari pemikiranpemikirannya. Pertama, mengenai hubungan antara akal dan wahyu yang saling menunjang. Kedua, mengenai pluralitas dan diversitas agama sebagai keniscayaan. Ketiga, mengenai watak keberagamaan yang tercermin dalam sensitivitas dan simpati terhadap penderitaan kelompok masyarakat lemah.

Pokok-pokok pemikiran di atas inilah yang melandasi Engineer dalam mengkonstruksi teologi pembebasan dalam Islam sebagaimana yang ia tunjukkan dalam bukunya Islam and Liberation Theology (1990). Menurut Engineer, teologi klasik cenderung kepada masalah-masalah yang abstrak dan elitis, berbeda dengan teologi pembebasan lebih cenderung kepada hal-hal yang konkret dan historis, dimana tekanannya ditujukkan kepada

\footnotetext{
${ }^{18}$ Asghar Ali Engineer, Islam ..., h. 99.

${ }^{19}$ Asghar Ali Engineer, Islam ..., h. 95.
} 
realitas kekinian, bukan realitas di alam maya. Bagi Engineer, teologi itu tidak hanya bersifat transendental, tetapi juga kontekstual. Teologi yang hanya berkutat pada wilayah metafisik akan tercerabut dari akar sosialnya. Baginya, teologi adalah refleksi dari kondisi sosial yang ada, dan dengan demikian suatu teologi adalah dikonstruksi secara sosial. Lebih lanjut menurut Engineer tidak ada teologi yang bersifat eternal yang selalu cocok dalam setiap kurun waktu dan sejarah.

Menurut Engineer, pandangan teologi itu juga tidak netral. Ia mempunyai keberpihakan, apakah kepada status quo atau kepada perubahan. Dengan kata lain, teologi itu dapat menjadi instrumen pembebas atau pembelenggu manusia. Semua itu tergantung kepada siapa yang mengkonstruksi dan menggunakannya. Keberpihakan teologi pembebasan sangat jelas, yaitu kepada mereka yang lemah dan tertindas. Ia diproyeksikan untuk perubahan, bukan untuk mengabdi kepada kekuasaan dan status quo. ${ }^{20}$

Jadi teologi pembebasan yang dipelopori Engineer ini merupakan usulan kreatif yang mengaitkan antara pentingnya paradigma baru dalam teologi yang memerangi penindasan dalam struktur sosio-ekonomi. Paradigma ini dilatarbelakangi oleh banyaknya fenomena arogansi kekuasaan, ketidak adilan, penindasan terhadap kaum lemah, pengekangan terhadap aspirasi masyarakat banyak, diskriminasi kulit, bangsa atau jenis kelamin, penumpukan kekayaan dan pemusatan kekuasaan dalam realitas masyarakat kontemporer. ${ }^{21}$

Lebih lanjut menurut Engineer, Islam adalah sebuah agama dalam pengertian teknis dan sebagai pendorong revolusi sosial yang memerangi struktur yang menindas. Tujuan dasarnya adalah persaudaraan yang universal (universal brotherhood), kesetaraan (equality) dan keadilan sosial (social justice). ${ }^{22}$ Oleh sebab itu teologi pembebasan dilatarbelakangi oleh masalah sosio-ekonomi, dan juga membicarakan masalah psiko-sosial. Struktur sosial saat ini sangat menindas dan harus diubah, sehingga menjadi lebih adil dengan perjuangan yang sungguh-sungguh, optimis, membutuhkan

\footnotetext{
${ }^{20} \mathrm{M}$. Agus Nuryatno, Asghar Ali Engineer:..., h. 2.

${ }^{21}$ Muhyar Fanani, Metode Studi Islam ......, h. 150.

${ }^{22}$ Asghar Ali Engineer, Islam ..., h. 33.
} 
kesabaran yang luar biasa, dan keyakinan yang kuat. ${ }^{23}$ Sebab secara psikologis, masyarakat yang hidup dalam lingkungan yang menindas akan cenderung frustrasi, pesimis, suka jalan pintas, dan lemah keyakinan. Kondisi psikis semacam ini harus diatasi dengan munculnya keyakinan teologis yang kuat agar mendorong mereka untuk giat mengubah nasibnya sendiri tanpa rasa frustrasi, dan menjadikan sumber motivasi kaum tertindas untuk mengubah keadaan mereka dan menjadikan kekuatan spiritual untuk mengomunikasikan dirinya secara berarti dengan memahami aspek-aspek spiritual yang lebih tinggi. ${ }^{24}$

Untuk itulah, teologi pembebasan sangat menekankan pada aspek praksis, yaitu kombinasi antara refleksi dan aksi, iman dan amal. Ia merupakan produk pemikiran yang diikuti dengan praksis untuk pembebasan. Jadi teologi pembebasan berupaya untuk menjadikan mereka yang lemah dan tertindas menjadi makhluk yang independen dan aktif. Karena hanya dengan menjadikan manusia yang aktif dan merdeka mereka dapat melepaskan diri dari belenggu penindasan. ${ }^{25}$

Sumber inspirasi teologi pembebasan menurut Enginer adalah alQur'an dan sejarah para rasul dan nabi Allah. Keberpihakan kedua sumber ini kepada kaum lemah tidak diragukan lagi. Al-Qur'an dengan jelas mengajarkan untuk menyatuni anak-anak yatim, orang-orang lemah, menegakkan keadilan, dan menekankan agar kapital itu tidak hanya berputar-putar disegelitir orang. Penekanan demikian persis yang dipraktekkan oleh para rasul dan nabi Allah. ${ }^{26}$

Dalam pandangan Engineer, para sejarawan membuktikan bahwa nabi Muhammad sebagai utusan Allah menggulirkan tantangan yang membahayakan saudagar-saudagar kaya suku Quraisy, yang berasal dari suku yang berkuasa di Mekah. Penolakan masyarakat Quraisy terhadap dakwah nabi Muhammad, menurut Engineer lebih dikarenakan faktor ekonomi daripada faktor agama. Masyarakat Quraisy yang menentang takut jika hegemoni ekonomi yang ada di genggaman mereka terganggu. Mereka

\footnotetext{
${ }^{23}$ Asghar Ali Engineer, Islam ..., h. 12.

${ }^{24}$ Muhyar Fanani, Metode Studi Islam ......, h. 151.

${ }^{25}$ M. Agus Nuryatno, Asghar Ali Engineer:..., h. 2.

${ }^{26}$ M. Agus Nuryatno, Asghar Ali Engineer:..., h. 2.
} 
menyombongkan diri dan mabuk dengan kekuasaan, melanggar normanorma kesukuan, dan tidak menghargai fakir miskin. ${ }^{27}$ Mengikuti pemikir Mesir Taha Husein, Engineer mengatakan bahwa jika nabi Muhammad hanya mendakwahkan Islam tentang keesaan Tuhan, tanpa menyerang sistem sosial-ekonomi, mengabaikan perbedaan antara yang kuat dan yang lemah, yang kaya dan yang miskin, tuan dan budak serta tidak mendesak para konglomerat Mekah untuk mendistribusikan sebagian kekayaan mereka kepada kaum lemah dan fakir miskin, maka mayoritas masyarakat Quraisy akan menerima kehadiran Islam yang di dakwahkan oleh nabi Muhammad saw. pada saat itu. ${ }^{28}$

Dalam semangat teologi pembebasan ini, Engineer mentransformasikan tiga konsep kerangka praksis teologi pembebasan, yaitu: Pertama, konsep tauhid. Bagi Engineer, tauhid tidak hanya mengacu pada keesaan Allah, namun juga pada kesatuan manusia (unity af mankind). Kesatuan bukan saja mengenai perkara akidah, tetapi adalah kesatuan dalam keadilan yang melintasi batas-batas keyakinan. Untuk itulah, dalam masyarakat tauhidi, tidak akan membenarkan dikriminasi, baik dalam bentuk ras, agama, kasta ataupun kelas sosial, sebab pembagian kelas, secara tidak langsung, menegaskan dominasi yang kuat atas yang lemah, kelas yang satu menindas yang lain, ketidakadilan, tirani, dan penindasan. Dominasi inilah yang menghalangi upaya pembentukan masyarakat yang adil. ${ }^{29}$ Lebih lanjut menurut Engineer, persoalan penindasan itu bukanlah persoalan antar pemeluk agama, akan tetapi lebih merupakan persoalan persoalan antara "penindas" dengan "yang tertindas". Sosok "penindas" dan "yang ditindas" itu bisa berasal dari agama manapun, ras apapun dan suku manapun. Dengan demikian, tauhid itu tidak hanya berdimensi sosialekonomi. Kafir tidak hanya mereka yang tidak percaya kepada Tuhan, tetapi juga termasuk mereka yang melawan segala usaha yang sungguh-sungguh untuk menata ulang struktur masyarakat agar lebih adil dan egaliter, tidak ada konsentrasi kekayaan di segelintir orang, serta tidak ada eksploitasi manusia atas manusia yang lain. ${ }^{30}$ Konsep tauhid inilah menurut Engineer

\footnotetext{
${ }^{27}$ Asghar Ali Engineer, Islam ..., h. 4.

${ }^{28}$ M. Agus Nuryatno, Asghar Ali Engineer:..., h. 2.

${ }^{29}$ Muhammad In Am Esha, Rethinking Kalam:....., h. 91.

${ }^{30} \mathrm{M}$. Agus Nuryatno, Asghar Ali Engineer:..., h. 3.
} 
yang sangat dekat dengan semangat al-Qur'an untuk menciptakan keadilan dan kebajikan (al-'adl wa al-ihsân). ${ }^{31}$

Kedua, konsep iman. Menurut Engineer kata iman berasal dari kata amn yang berarti selamat, damai, perlindungan, dapat diandalkan, terpercaya dan yakin. ${ }^{32}$ Untuk itu, iman tidak hanya soal kepercayaan kepada Allah, tetapi orang yang beriman harus dapat dipercaya, berusaha menciptakan kedamaian dan ketertiban, dan menyakini nilai-nilai kebaikan dalam kehidupan. Iman kepada Allah akan mengantarkan manusia pada perjuangan yang sungguh-sungguh untuk menciptakan masyarakat yang adil dan sejahtera. Jadi iman tidak hanya berkutat pada wilayah keyakinan an sich, tetapi juga mengandung dimensi sosiologis dan ekonomis. Lebih lanjut menurut Engineer, orang kafir (kufr), adalah orang yang tidak hanya menampik eksistensi Allah, tetapi juga yang menantang usaha-usaha jujur untuk membentuk masyarakat, menghapus akumulasi dalam segala bentuknya. "Seseorang yang secara formal beriman kepada Allah, tetapi memperturutkan hawa nafsu dengan menimbun kekayaan dengan menindas orang lain, dan gemar melakukan konsumtif yang menyolok mata, sementara yang lain menderita kelaparan, juga termasuk kafir (kufr)." tegas Engineer. ${ }^{33}$ Ketiga, konsep jihad. Jihad makna literernya perjuangan. ${ }^{34}$ Teologi pembebasan memaknai jihad sebagai perjuangan menghapus eksploitasi, korupsi, dan berbagai bentuk kezaliman. Perjuangan yang harus dilakukan secara dinamis dan istiqamah, agar kelaliman yang dilakukan manusia sirna dari muka bumi. Untuk itu teologi pembebasan tidak memaknai jihad sebagai perang militer, tetapi aktivitas dinamis progresif untuk melakukan pembebasan masyarakat dari realitas penindasan yang menimpa mereka. Jihad untuk pembebasan, bukan jihad untuk berperang (aggression) ${ }^{35}$ Dengan demikian, menurut Engineer struktur sosial yang sangat menindas harus dirubah, sehingga menjadi lebih adil dengan perjuangan yang sungguhsungguh, yang sering kali meminta pengorbanan. Perjuangan tidak mudah,

${ }^{31}$ Asghar Ali Engineer, Islam ..., h. 11.

${ }^{32}$ Asghar Ali Engineer, Islam ..., h. 12.

${ }^{33}$ Muhammad In Am Esha, Rethinking Kalam:....., h. 93.

${ }^{34}$ Atabik Ali dan Ahmad Zuhdi Muhdlor, Kamus Kontemporer Arab-Indonesia, (Yogyakarta: Multi Karya Grafika, 1998), h. 702.

${ }^{35}$ Muhammad In Am Esha, Rethinking Kalam:....., h. 92. 
karena membutuhkan keyakinan, optimisme dan kesabaran yang luar biasa. Sebab keyakinan, optimisme dan kesabaran merupakan hal yang fundamental dalam dakwah Islam. Jadi kesabaran dimaksud adalah kesabaran yang ditujukkan selama mengadakan perjuangan untuk menciptakan perubahan sosial, merupakan sebuah senjata psikologis yang sangat kuat dalam menghadapi segala kesulitan. ${ }^{36}$

\section{Penutup}

Engineer dikenal sebagai sosok pemikir Islam kontemporer dan juga seorang aktivis sosial di India, yang mempunyai perhatian besar terhadap problema-problema sosial. Situasi dan kondisi masyarakat Muslim India yang marjinal, terkebelakang, tradisional dan sikap defensif-konservatif dalam menghadapi realitas, menimbulkan keprihatinan tersendiri bagi Engineer. Ia merancang teologi pembebasan dalam konteks pemikiran Islam, dimana konstruksi pemikiran yang dibangunnya konsern pada upaya pembelaan terhadap kaum tertindas.

Pemikiran Engineer yang ditransformasikan menjadi tiga kerangka praksis teologi pembebasan, yaitu: Pertama, konsep tauhid, yang tidak hanya mengacu pada keesaan Allah, namun juga pada kesatuan manusia (unity of mankind). Masyarakat taubidi, mengakui dan menjamin kesataraan manusia, dan tidak akan membenarkan adanya diskriminasi dalam bentuk apapun, baik terkait ras, agama, kasta ataupun kelas sosial. Kedua, konsep iman, tidak hanya dimaknai soal percaya kepada Allah, tetapi orang yang beriman harus dapat dipercaya, berusaha menciptakan kedamaian dan ketertiban, bersungguh-sungguh untuk menciptakan masyarakat yang adil dan sejahtera, dan menyakini nilai-nilai kebaikan dalam kehidupan. Sedangkan makna kafir bagi Engineer, adalah orang yang tidak hanya menentang eksistensi Allah, tetapi juga yang menentang usaha-usaha jujur untuk membentuk masyarakat, menghapus akumulasi kapital, menentang penindasan, dan mengakhiri eksploitasi dalam segala bentuk. Ketiga, konsep jihad, yang dimaknai sebagai perjuangan yang dilakukan secara dinamis dan istiqamah, untuk menghapus eksploitasi, korupsi, dan berbagai bentuk

\footnotetext{
${ }^{36}$ Asghar Ali Engineer, Islam ..., h. 12.
} 
kezaliman. Teologi pembebasan tidak memaknai jihad sebagai perang militer, atau bukan jihad untuk berperang (eggression). Dan tidak berlebihan jika dikatakan, teologi pembebasan ala Engineer ini, adalah teologi humanis, sebuah paradigma teologis dan praksis bagi pembebasan manusia []

\section{DAFTAR PUSTAKA}

Ali, Atabik dan Ahmad Zuhdi Muhdlor, (1998), Kamus Kontemporer ArabIndonesia, Yogyakarta: Multi Karya Grafika.

Dewanto, Nugroho dan Iqbal Muhtarom, (2008), Anti MUI: Islam Yes, MUI No, Surga Bukan Monopoli Muslim, Wawancara dengan Asghar Ali Engineer, Majalah Tempo, 20 Agustus 2008.

Effendi, Djohan, Memikirkan Kembali Asumsi Pemikiran Kita, Kata Pengantar, Asghar Ali Engineer, Islam dan Pembebasan, dalam http:// media.isnet.org/islam/Etc/Pengantar

Engineer, Asghar Ali, (2000), The Rights of Women in Islam, Terj. Farid Wajidi Yogyakarta: Pustaka Pelajar.

—, (2003), Islam dan Teologi Pembebasan, Terj. Agung Prihantoro, Yogyakarta: Pustaka Pelajar.

Fanani, Muhyar, (2008), Metode Studi Islam Aplikasi Sosiologi Pengetahuan Sebagai Cara Pandang, Yogyakarta: Pustaka Pelajar.

Gaus AF, Ahmad, (2009), Sang Pelintas Batas Biografi Djohan Effendi, Jakarta: ICRP dan Kompas,

In Am Esha, Muhammad, (2006), Rethinking Kalam: Sejarah Sosial Pengetahuan Islam, Mecermati Dinamika dan Aras Perkembangan Kalam Kontemporer, Yogyakarta: eLSAQ Press.

Shihab, M. Quraish, (2002), Tafsir al-Mishbah Pesan, Kesan dan Keserasian alQur'an, Volume 13, Jakarta: Lentera Hati.

Syarif, Jamal, (2004), Pemikiran Asghar Ali Engineer Tentang Hak-Hak Perempuan Dalam Islam, Khazanah Jurnal Ilmiah Keislaman dan 
Kemasyarakatan, Volume III Nomor 1, Januari-Pebruari 2004, Banjarmasin: IAIN Antasari, 2004.

Nuryatno, M. Agus, Asghar Ali Engineer: Sang Teolog Pembebasan, dalam http://www.mailarchive.com/kmnu2000@yahoogroups.com/ msg01. 